OPEN ACCESS

Edited by:

Sandra Torriani,

Università degli Studi di Verona, Italy

Reviewed by:

Matthias Sipiczki,

University of Debrecen, Hungary

Jyoti Prakash Tamang,

Sikkim University, India

*Correspondence:

Giuseppe Blaiotta

blaiotta@unina.it

Specialty section:

This article was submitted to

Food Microbiology,

a section of the journal

Frontiers in Microbiology

Received: 30 January 2016

Accepted: 12 May 2016

Published: 27 May 2016

Citation:

Aponte M and Blaiotta G (2016) Potential Role of Yeast Strains Isolated

from Grapes in the Production of

Taurasi DOCG.

Front. Microbiol. 7:809

doi: 10.3389/fmicb.2016.00809

\section{Potential Role of Yeast Strains Isolated from Grapes in the Production of Taurasi DOCG}

\author{
Maria Aponte ${ }^{1}$ and Giuseppe Blaiotta ${ }^{2 *}$ \\ ${ }^{1}$ Sezione di "Microbiologia", Dipartimento di Agraria, Università degli Studi di Napoli Federico II, Napoli, Italy, ${ }^{2}$ Sezione di \\ "Scienze della Vigna e del Vino", Dipartimento di Agraria, Università degli Studi di Napoli Federico II, Avellino, Italy
}

Twelve samples of Aglianico grapes, collected in different locations of the Taurasi DOCG (Appellation of Controlled and Guaranteed Origin) production area were naturally fermented in sterile containers at room temperature. A total of 70 yeast cultures were isolated from countable WL agar plates: 52 in the middle of the fermentation and 18 at the end. On the basis of ITS-RFLP analysis and ITS sequencing, all cultures collected at the end of fermentations were identified as Saccharomyces (S.) cerevisiae; while, the 52 isolates, collected after 1 week, could be referred to the following species: Metschnikowia (M.) pulcherrima; Starmerella (Star.) bacillaris; Pichia (P.) kudriavzevii; Lachancea (L.) thermotolerans; Hanseniaspora (H.) uvarum; Pseudozyma (Pseud.) aphidis; S. cerevisiae. By means of Interdelta analysis, 18 different biotypes of $S$. cerevisiae were retrieved. All strains were characterized for ethanol production, $\mathrm{SO}_{2}$ resistance, $\mathrm{H}_{2} \mathrm{~S}$ development, $\beta$-glucosidasic, esterasic and antagonistic activities. Fermentation abilities of selected strains were evaluated in micro-fermentations on Aglianico must. Within non-Saccharomyces species, some cultures showed features of technological interest. Antagonistic activity was expressed by some strains of $M$. pulcherrima, $L$. thermotolerans, $P$. kudriavzevii, and S. cerevisiae. Strains of $M$. pulcherrima showed the highest $\beta$-glucosidase activity and proved to be able to produce high concentrations of succinic acid. $L$. thermotolerans produced both succinic and lactic acids. The lowest amount of acetic acid was produced by M. pulcherrima and L. thermotolerans; while the highest content was recorded for H. uvarum. The strain of Star. bacillaris produced the highest amount of glycerol and was able to metabolize all fructose and malic acid. Strains of $M$. pulcherrima and H. uvarum showed a low fermentation power (about 4\%), while, L. thermotolerans, Star. Bacillaris, and P. kudriavzevii of about 10\%. Significant differences were even detected for $\mathrm{S}$. cerevisiae biotypes with respect to $\mathrm{H}_{2} \mathrm{~S}$ production, antagonistic activity and $\beta$-glucosidase activity as well as for the production of acetic acid, glycerol and ethanol in micro-vinification experiments.

Keywords: grapes, yeast microflora, Aglianico, identification, biotyping, wine fermentation 


\section{INTRODUCTION}

Wine composition and quality are affected by several intrinsic and extrinsic variables, many of which are microbiologically mediated. Spontaneous alcoholic fermentation of grape must is a complex process owing to metabolic activities of different groups of microorganisms including filamentous fungi (i.e., Botrytis spp.), yeasts, and bacteria (lactic and acetic acid bacteria) originating from grapes, soil, and cellar equipment (Mills et al., 2008). The physiological properties of these complex microbial consortia lead to the formation of metabolites and to the transformation of grape molecules, thus influencing the sensorial properties (color, aroma, flavor, structure, and body) of the final product (Pretorius, 2000; Fleet, 2003). Due to the sequential action of different yeast species/strains, naturally present on the berries grapes or in the winery, the outcome of spontaneous alcoholic fermentation is difficult to predict and therefore, results are often unreproducible (Pretorius, 2000). To address this issue, many winemakers use pure yeast cultures (starters) of $S$. cerevisiae or S. bayanus species, which are inoculated into the must after pressing. The use of starter cultures allows a more rapid and complete grape must fermentation and a higher degree of reproducibility in the atmosphere of specific wines can be achieved (Pretorius, 2000; Fleet, 2008; Suarez-Lepe and Morata, 2012). However, there is some controversy about the use of commercial wine yeasts due to the lack of some desirable traits provided by natural or spontaneous fermentation (Pretorius, 2000). Moreover, the continuous use of a limited number of strains as commercial starter cultures by wine industry is causing the erosion of the microbial diversity. The study and the preservation of the wine yeasts biodiversity have recently become matter of growing interest (Di Maio et al., 2012). The maintenance of the biological patrimony is essential to obtain starter strains able to fully develop the typical sensory profile of wines originating from different grapevine cultivars, as well as to preserve a gene pool of paramount importance for any yeastmediated process (Pretorius, 2000; Marinangeli et al., 2004). Such criticism is providing new challenges to enhance the appeal and value of wine produced by this fermentation technology. As reviewed by Fleet (2008), this may be achieved by selecting novel yeast starter cultures from natural wine environment and by leading the fermentations with mixtures of yeast species (including Saccharomyces and non-Saccharomyces) and strains, for flavor modulation, volatile acidity decreasing, malic and lactic acids production or degradation.

The present survey was focused on Taurasi DOCG (Appellation of Controlled and Guaranteed Origin), a wine produced within a small area of the Campania Region (Irpinia district) by a starter-led fermentation technology. Taurasi DOCG, as reported in the production specifications (Ministerial Decree 11 March 1993; G.U. n. 72 of 27 March 1993), is a red wine manufactured by Vitis vinifera cv. Aglianico (at least 85\%) exclusively cultured in 17 municipalities (Taurasi, Bonito, Castelfranci, Castelvetere sul Calore, Fontanarosa, Lapio, Luogosano, Mirabella Eclano, Montefalcione, Montemarano, Montemileto, Paternopoli, Pietradefusi, Sant'Angelo all'Esca, San Mango sul Calore, Torre le Nocelle e Venticano) of the
Avellino province. To explore the natural yeast diversity, grapes from 12 different vineyards were analyzed. Molecular methods were applied for isolates identification as well as for strains biotypization within the $S$. cerevisiae species. The potential winemaking role of isolated yeast strains was assessed by evaluation of oenological traits and of the behavior in micro-fermentation trials in Aglianico must.

\section{MATERIALS AND METHODS}

\section{Sampling and Yeast Isolation}

Samples of Aglianico grapes were collected (end of October 2012) in 12 vineyards located in the municipalities where this variety is cultivated (Table 1 ). The origin and ${ }^{\circ}$ Babo of grape samples are reported in Table 1. Samples (about 20 bunches) were collected by using sterile gloves along the two diagonals of the vineyard, placed in sterile plastic bags and transferred in the laboratory within few hours. Grapes were manually pressed in the collection bag, and, after the addition of potassium metabisulfite $(100 \mathrm{mg} / \mathrm{kg})$, were incubated at room temperature $\left(18-22^{\circ} \mathrm{C}\right)$. During incubation the sugar content $\left({ }^{\circ} \mathrm{Babo}\right)$ was monitored and, after 9 days of fermentation, must samples were analyzed. After sampling, partially fermented musts were combined into one sterile container and left to ferment until complete sugars consumption (mix-wine).

Must samples and mix-wine were serially diluted in quarter strength Ringer's solution (Oxoid, Basingstoke, UK) and spreadplated on WL-nutrient agar (Oxoid). After incubation at $28^{\circ} \mathrm{C}$ for 5 days, countable plates (15-150 colonies/plate) were used for viable counts and yeasts isolation. Colonies showing different morphology and/or color were all selected, independently by their number. In mix-wine sample, all colonies $\left(\mathrm{n}^{\circ} 18\right)$ grown in one of the two countable plates were considered. Cultures were purified by repetitive streaking on WL-nutrient agar.

Yeast cultures were preserved on WL-nutrient agar slants, stored at $4{ }^{\circ} \mathrm{C}$ and sub-cultured every 3 months. Before each test, strains were cultured twice in YPD (yeast extract $10 \mathrm{~g} / \mathrm{l}$, peptone $20 \mathrm{~g} / \mathrm{l}$, dextrose $20 \mathrm{~g} / \mathrm{l})$.

\section{Yeast Strains Molecular Identification and Typing}

DNA was isolated as previously reported by Aponte and Blaiotta (2016). Preliminary molecular identification of yeast strains was achieved by ITS (ITS1-5.8S-ITS2)-rDNA RFLP (EsteveZarzoso et al., 1999; Csoma and Sipiczki, 2008) analysis using restriction endonucleases Hae III, Hinf I, and Cfo I. In addition, enzymes Dde I and $M b o$ I were used for the characterization of Hanseniaspora and Candida spp, respectively. The identification of non-Saccharomyces cultures was obtained by ITS-rDNA sequencing. Genetic diversity within Saccharomyces isolates was assessed by Interdelta analysis (Legras and Karst, 2003).

\section{Yeast Strains Technological Characterization}

Ethanol tolerance was evaluated in YPD broth containing ethanol concentrations ranging from 4 to $15 \% \quad(\mathrm{v} / \mathrm{v})$. 
TABLE 1 | Origin of grape samples and basic physico-chemical characteristics of the musts.

\begin{tabular}{|c|c|c|c|c|c|}
\hline \multirow[t]{2}{*}{ Grape Sample } & \multirow[t]{2}{*}{ Origin (Municipality) } & & \multicolumn{3}{|c|}{ Must characteristics } \\
\hline & & & ${ }^{\circ}$ Babo & $\mathrm{pH}$ & Total acidity ${ }^{a}$ \\
\hline 1 & & Mirabella Eclano & 20.9 & 3.18 & 9.57 \\
\hline 2 & & Pietradefusi & 20.8 & 3.41 & 9.26 \\
\hline 3 & & Castelfranci & 19.4 & 3.26 & 9.65 \\
\hline 4 & & Montemarano & 20.7 & 3.18 & 9.58 \\
\hline 5 & & Lapio & 20.3 & 3.22 & 9.05 \\
\hline 6 & & Montemileto & 21.6 & 3.21 & 8.78 \\
\hline 7 & & Castelvetere sul Calore & 20.6 & 3.35 & 8.56 \\
\hline 8 & & Paternopoli & 21.6 & 3,32 & 9.36 \\
\hline 9 & & San Mango sul Calore & 19.8 & 3.08 & 11.21 \\
\hline 10 & & Luogosano & 19.0 & 3.11 & 10.20 \\
\hline 11 & & Taurasi & 20.8 & 3.34 & 8.79 \\
\hline 12 & & Fontanarosa & 19.8 & 3.21 & 10.26 \\
\hline
\end{tabular}

Location of Taurasi production area and of vineyards where grape sampling was carried out is reported on the map (collection sites are indicated by numbers). ${ }^{a} \mathrm{~g} / \mathrm{l}$ of tartaric acid $(25 \mathrm{ml}$ of wine sample and $0.25 \mathrm{~N} \mathrm{NaOH})$.

After incubation at $20^{\circ} \mathrm{C}$ for $72 \mathrm{~h}$, growth was assessed by spectrophotometry at white light $(600 \mathrm{~nm})$. Sulfur dioxide $\left(\mathrm{SO}_{2}\right)$ tolerance was evaluated in YPD broth adjusted at pH 3.30 with tartaric and malic acids (1:1) and containing potassium metabisulfite concentrations ranging from 50 to $200 \mathrm{mg} / \mathrm{l}$. Growth was evaluated, after incubation at $20^{\circ} \mathrm{C}$ for $72 \mathrm{~h}$, by spectrophotometry at white light $(600 \mathrm{~nm})$. Hydrogen sulfide $\left(\mathrm{H}_{2} \mathrm{~S}\right)$ production was estimated on Biggy agar (Oxoid) after incubation at $28^{\circ} \mathrm{C}$ for $48 \mathrm{~h}$. For browning description, the following codes were used: low production, snow-white color; medium production, hazelnut-brown color; high production, rust-coffee color (Aponte and Blaiotta, 2016). Type of growth was estimated in tyndallized $\left(100^{\circ} \mathrm{C}\right.$ $\times 5$ min $\times 3$ times $)$ must $\left(21^{\circ}\right.$ Brix, $\left.\mathrm{pH} 3.50\right)$ after 4 days at $25^{\circ} \mathrm{C}$. Antagonistic activity was assessed as described by Sangorrin et al. (2001) using S. cerevisiae CECT 1890 as sensitive strain.

$\beta$-glucosidase activities were evaluated on media containing cellobiose (CELL), 4-methylumbelliferyl-b-D-glucopyranoside (MUG), arbutin (ARB), esculin (ESC), or p-nitrophenyl $\beta$-Dglucopyranoside (pNPG) (Fluka, Milan, Italy), according to the method proposed by Fia et al. (2005) and Hernandez et al. (2002). Esterase activity was evaluated on a medium containing Tween 80 as described by Slifkin (2000).

In order to estimate the percentage of similarity among isolates, data were subject to cluster analysis (Average Linkage Method). A correlation matrix was constructed using the formula described by Upholt (1977) and Nei and Li (1979): $F_{x y}=$ $\left(2 n_{x y}\right) /\left(n_{x}+n_{y}\right)$ where $F_{x y}$ is the proportion of common molecular markers of molecular biotypes compared ( $\mathrm{x}$ and $\mathrm{y}$ ), $\mathrm{n}_{\mathrm{xy}}$ is the number characters shared by both isolates $x$ and $y$ and $n_{x}$ and $\mathrm{n}_{\mathrm{y}}$ are the total of number characters of observed in isolates $\mathrm{x}$ and $\mathrm{y}$, respectively [in our case $\left(\mathrm{n}_{\mathrm{x}}+\mathrm{n}_{\mathrm{y}}\right)=(10+10)=20$ ] The resulting correlation matrix was analyzed by Systat 5.2.1 software.

\section{Fermentation Performances of Selected Yeast Strains}

Fermentation vigor (FV) and fermentation power (FP) were evaluated in micro-fermentation trials in Aglianico must $\left({ }^{\circ} \mathrm{Brix}\right.$ 24, $\mathrm{pH} 3.09$; total acidity $9.98 \mathrm{~g} / \mathrm{l}$ of tartaric acid). Strains, cultured twice in YPD medium, were used to inoculate (about $6 \mathrm{Log}$ $\mathrm{CFU} / \mathrm{ml}) 100 \mathrm{ml}$ of tyndallized $\left(100^{\circ} \mathrm{C}\right.$ for $3 \mathrm{~min}$ for 3 times $)$ must in $250 \mathrm{ml}$ Erlenmeyer flasks closed with a Müller valve filled with sulfuric acid. During incubation (3 days at $23^{\circ} \mathrm{C}$ ), flasks were handle stirred for $30 \mathrm{~s}$ every $12 \mathrm{~h}$. Weight loss, due to $\mathrm{CO}_{2}$ escaping from the system, was quantified to monitor the fermentation kinetics. Fermentation was considered concluded when no weight loss was any longer recorded within $24 \mathrm{~h}$. FV was expressed as grams of $\mathrm{CO}_{2}$ produced in $100 \mathrm{ml}$ of must during the first $72 \mathrm{~h}$ of fermentation, while FP was expressed as grams of $\mathrm{CO}_{2}$ produced until the end of fermentation. Each trial was performed in triplicate. At the end of micro-fermentations, concentrations of citric, tartaric, malic, lactic, and succinic acids and of glucose, fructose, glycerol, 2,3-butanediol and ethanol were determined by HPLC analyses as previously described by Aponte and Blaiotta (2016).

\section{RESULTS}

The aims of the present study were the yeast microbiota exploration of Aglianico grapes, grown in the Taurasi DOCG area and the evaluation of potential technological contribute of autochthonous yeast strains in winemaking. Grapes were sampled in 12 different vineyards located in area of production of this typical wine (Table 1); physico-chemical characteristics of relative musts are reported in Table 1. Musts showed a high sugar content (20.4 $\pm 0.8{ }^{\circ}$ Babo as average value) and were characterized by low $\mathrm{pH}(3.2 \pm 0.1)$ and high total acidity $(9.5 \pm$ $0.8 \mathrm{~g} / \mathrm{l}$ ). After 9 days of fermentation at room temperature, musts 
showed highly different residual sugar contents $\left({ }^{\circ}\right.$ Babo from 7 to 13) and alcoholic degrees (Malligand ebullioscope degree from 2 to $8 \% \mathrm{vol} / \mathrm{vol}$ ) (Table 2). In fact, 9 musts out of 12 still contained more than a half of the initial sugar content. Viable yeast counts ranged from 6.4 to $8.2 \mathrm{Log} \mathrm{CFU} / \mathrm{ml}$ (Table 2).

The mix-wine was obtained by joining partially fermented musts whose fermentation was allowed to proceed for further 30 days, namely until the sugar content did not change for $48 \mathrm{~h}$. The mix-wine reached an alcoholic degree of $12.8 \% \mathrm{vol} / \mathrm{vol}$ (Table 2) and still contained a high concentration of residual sugars $(10.7 \mathrm{~g} / \mathrm{l}$ of glucose and $11.2 \mathrm{~g} / \mathrm{l}$ of fructose) and acetic acid $(3.2 \mathrm{~g} / \mathrm{L})$ as determined by HPLC analysis. Yeast loads were still high as well (around $5 \mathrm{Log} \mathrm{CFU} / \mathrm{ml}$ ). Fifty-two yeast cultures were isolated from partially fermented musts, on the basis of colony morphology and color on counting plates, and purified (Table 2). For mix-wine, all colonies $\left(n^{\circ} 18\right)$ present in one countable plate seeded with the highest dilution $\left(10^{-4}\right)$ were isolated (Table 2). According to ITS-RFLP analysis, yeast cultures could be clustered in seven groups (Supplementary Table $\mathrm{S} 1$ ). Forty-nine isolates were identified as $S$. cerevisiae on the basis of their ITS-RFLP patterns (Supplementary Table S1). NonSaccharomyces entities were all subjected to ITS sequence analysis to confirm presumptive identification obtained according to ITSRFLP (Supplementary Table S1). Yeast species isolated in each sample are summarized in Table 2. Since all types of colonies were selected, even those showing slight differences on WL agar, a medium supposed to be highly differential (Pallmann et al., 2001); and since colonies were all picked by plates seeded with the highest dilutions, species recorded could be confidently considered as components of the dominant cultivable microbiota in that environment. Specifically, in must samples characterized by an alcoholic degree higher than $5 \%$ (musts $1,8,10,11$, and 12), only $S$. cerevisiae or $S$. cerevisiae and H. uvarum (must 8 ) were isolated. In other samples, $S$. cerevisiae was co-isolated with at least further two yeast species (musts 2, 3, 4, and 7) or was not detected (musts 5, 6, and 9). In the latter case, yeast microbiota of musts appeared to be characterized by a mix yeast population (P. kudriavzevii, L. thermotolerans, and H. uvarum or $M$. pulcherrima and L. thermotolerans) or by a single species ( $M$. pulcherrima) (Table 2).

As expected, in mix wine, with an alcoholic degree of $12.8 \%$, only isolates referable to $S$. cerevisiae species were retrieved. The $49 \mathrm{~S}$. cerevisiae isolates (38 from must samples and 18 from mix wine) were typed by Interdelta analysis to evaluate their genetic diversities and to determine their clonal relationships. Supplementary Figure S1 shows patterns displayed by $S$. cerevisiae isolates detected in mix-wine at the end of fermentation. In must samples $\left(\mathrm{n}^{\circ} 38\right)$, a total of 13 different biotypes were detected (Table 3, patterns "I"-“XIII"). In several musts $(1,2,8,10,11$, and 12) more than one S. cerevisiae biotype occurred. Nevertheless, in some cases, the same biotype was detected in different samples, i.e., "V" in musts 3 and 8; "VII" in musts 7 and 8; "XII" in musts 11 and 12 (Table 3). Moreover, it is noteworthy that must samples $3,7,8$, and 11,12 were produced from grapes collected in closely located vineyards (Table 1). In mix wine, a total of eight different biotypes, out of 18 isolates, were retrieved: three ("IV," "VII," and "XII") already detected in must samples and five new ("XIV"-“XVIII") (Table 3). The biotype "XIV" showed the highest occurrence: 10 isolates out 18 analyzed.

A total of 43 isolates (22 non-Saccharomyces, 13 S. cerevisiae isolates from musts samples and eight from mix-wine) were

TABLE 2 | Physico-chemical and microbiological characteristics of musts and mix wine after partial fermentation (9 and 30 days, respectively).

\begin{tabular}{|c|c|c|c|c|c|c|c|c|c|c|c|}
\hline \multirow{2}{*}{$\begin{array}{l}\text { Must } \\
\text { sample }\end{array}$} & \multirow[t]{2}{*}{${ }^{\circ}$ Babo } & \multirow{2}{*}{$\begin{array}{c}\text { Ethanol } \\
(\% \text { vol/vol })^{a}\end{array}$} & \multirow{2}{*}{$\begin{array}{c}\text { Yeast loads } \\
\text { (Log CFU/ml) }^{\text {b }}\end{array}$} & \multirow{2}{*}{$\begin{array}{c}\text { No. of } \\
\text { isolates }^{c}\end{array}$} & \multicolumn{7}{|c|}{ Species $^{d}$} \\
\hline & & & & & M. pulcherrima & $\begin{array}{c}\text { Star. } \\
\text { bacillaris }\end{array}$ & P. kudriavzevii & L. thermotolerans & H. uvarum & $\begin{array}{l}\text { Pseud. } \\
\text { aphidis }\end{array}$ & S. cerevisiae \\
\hline 1 & 7.8 & 7.9 & $7.21 \pm 0.21$ & 4 & & & & & & & 4 \\
\hline 2 & 13.8 & 4.2 & $8.16 \pm 0.01$ & 7 & & & & 1 & & 2 & 4 \\
\hline 3 & 14.3 & 3.1 & $7.36 \pm 0.05$ & 4 & & 1 & & 1 & & & 2 \\
\hline 4 & 17.3 & 2.1 & $7.33 \pm 0.00$ & 5 & 1 & & & & 2 & & 2 \\
\hline 5 & 13.8 & 3.9 & $7.25 \pm 0.15$ & 5 & & & 3 & 1 & 1 & & \\
\hline 6 & 17.3 & 2.6 & $6.37 \pm 0.02$ & 2 & 2 & & & & & & \\
\hline 7 & 15.1 & 3.3 & $6.81 \pm 0.51$ & 5 & 1 & & & 1 & 1 & & 2 \\
\hline 8 & 10.8 & 6.4 & $6.80 \pm 0.52$ & 5 & & & & & 1 & & 5 \\
\hline 9 & 14.7 & 3.1 & $6.90 \pm 0.44$ & 3 & 1 & & & 2 & & & \\
\hline 10 & 6.9 & 7.3 & $7.80 \pm 0.06$ & 4 & & & & & & & 4 \\
\hline 11 & 11.7 & 5.4 & $7.77 \pm 0.19$ & 4 & & & & & & & 4 \\
\hline 12 & 6.9 & 7.8 & $8.05 \pm 0.04$ & 4 & & & & & & & 4 \\
\hline Mix-wine & 1.8 & 12.8 & $5.30 \pm 0.06$ & 18 & & & & & & & 18 \\
\hline
\end{tabular}

${ }^{a}$ Ebullioscopic (Malligand).

${ }^{b}$ Counts on WL Nutrient agar $\left(28^{\circ} \mathrm{C}\right.$ for 5 days).

${ }^{c}$ Selection on the basis of colony colur and morphology from countable plates (15-150 colonies/plate).

${ }^{d}$ Identifications obtained by ITS-RFLP and ITS sequencing analyses (see Supplementary Table S1). 
TABLE 3 | Distribution of S. cerevisiae biotypes, detected by Interdelta analysis, in analyzed samples.

\begin{tabular}{|c|c|c|c|c|c|c|c|c|c|c|c|c|c|c|c|c|c|c|c|}
\hline \multirow[t]{2}{*}{ Must } & \multirow[t]{2}{*}{ No. of isolates } & \multicolumn{18}{|c|}{ S. cerevisiae biotypes } \\
\hline & & I & II & III & IV & $\mathbf{v}$ & VI & VII & VIII & IX & $\mathbf{x}$ & $\mathbf{X I}$ & XII & XIII & XIV & $\mathbf{X V}$ & $\mathbf{X V I}$ & XVII & XVIII \\
\hline 1 & 4 & $2^{a}$ & 2 & & & & & & & & & & & & & & & & \\
\hline 2 & 4 & & & 2 & 2 & & & & & & & & & & & & & & \\
\hline 3 & 2 & & & & & 2 & & & & & & & & & & & & & \\
\hline 4 & 2 & & & & & & 2 & & & & & & & & & & & & \\
\hline 7 & 2 & & & & & & & 2 & & & & & & & & & & & \\
\hline 8 & 5 & & & & & 3 & & 2 & & & & & & & & & & & \\
\hline 10 & 4 & & & & & & & & 1 & 3 & & & & & & & & & \\
\hline 11 & 4 & & & & & & & & & & 1 & 1 & 2 & & & & & & \\
\hline 12 & 4 & & & & & & & & & & & & 3 & 1 & & & & & \\
\hline Mix-wine & 18 & & & & 1 & & & 1 & & & & & 1 & & 10 & 2 & 1 & 1 & 1 \\
\hline
\end{tabular}

a Number of isolates showing the same Interdelta pattern.

characterized for biochemical features of oenological interest (Table 4). Strains belonging to the same species showed similar ethanol resistance: M. pulcherrima (4-5\%); Pseud. aphidis (a yeast like fungi, classified in the Ustilaginales) (6\%); $H$. uvarum (7\%); Star. bacillaris (synonym Candida zemplinina), and L. thermotolerans (10\%); P. kudriavzevii (10-12\%); S. cerevisiae (15-16\%). All strains were able to grow in YPD ( $\mathrm{pH} 3.30$ ) containing $200 \mathrm{mg} / \mathrm{l}$ of potassium metabisulfite and most of them grew in tyndallized must as dispersed cells. One isolate (T28) of P. kudriavzevii grew on the surface; while the two Pseud. aphidis cultures were flocculent (Table 4). $H$. uvarum strains were low $\mathrm{H}_{2} \mathrm{~S}$ producers, $M$. pulcherrima fair producers, while the Star. bacillaris culture and those belonging to the species Pseud. aphidis were high producers (Table 4). Behavior within the species P. kudriavzevii, L. thermotolerans, and $S$. cerevisiae proved to be strain-dependent. Antagonistic activity was expressed by some isolates of $M$. pulcherrima (two out five), L. thermotolerans (four out six), P. kudriavzevii (one out three), and S. cerevisiae (6 out 21). Cellobiose was hydrolyzed only by $M$. pulcherrima and $H$. uvarum isolates; while arbutin just by $M$. pulcherrima. For the other beta-glucosides used as precursors (4-methylumbelliferyl-b-D-glucopyranoside, esculin, and $\mathrm{p}$-nitrophenyl $\beta$-D-glucopyranoside) different attitudes were recorded depending on the strain: the Star. bacillaris strain showed a low response, while Pseud. aphidis strains exhibited an high beta-glucosidase activity on these substrate (Table 4). Finally, only in Pseud. aphidis strains expressed esterase activity on a Tween 80 -based medium.

The percentage of similarity among isolates, on the basis of technological traits, was evaluated by cluster analysis (Average Linkage Method) and the UPGMA dendrogram depicted in Figure 1 was obtained. Isolates of the same species clustered at a similarity level higher than $75 \%$, with the unique exception of $P$. kudriavzevii strains which were positioned in two different clusters: T24 and T25 in cluster 4 and T28 in cluster 6. Actually, T28 differed from the other two isolates for ethanol resistance (12\%), type of growth (superficial), $\mathrm{H}_{2} \mathrm{~S}$ production (high), antagonistic activity (positive), and high beta-glucosidase activity (Table 4). In spite of the different origin and of the genetic diversity as emerged by Intedelta analysis, strains of $S$. cerevisiae grouped in a single cluster (cluster 5 ) with a quite high similarity level (80\%) (Figure 1). No direct correlation between cluster position and origin of isolates was pointed out, even if, in some cases strains, strains with the same origin (T51 and T52, T8 and T5, T46 and T47; isolated from M11, M2, and M10, respectively) clustered very closely (>90\%) (Figure 1). Surprisingly, strains showing the same Interdelta pattern (T8 and MW3, pattern "IV"; T34 and MW16, pattern "VII"; T54 and MW5, pattern "XII") showed technological traits poorly different (Figure 1). Combining data of Table 4 and Figure 1, 23 strains (10 non-Saccharomyces and 13 S. cerevisiae) were selected for the evaluation of the fermentation performances in Aglianico must containing about $240 \mathrm{~g} / \mathrm{l}$ of reducing sugars and, therefore, an ethanolic potential of about 14\% ( $\mathrm{vol} / \mathrm{vol}$ ) (Table 5). Despite of their high beta-glucosidase and esterase activity, Pseud. aphidis strains were excluded because did not show fermentative activity. With exception of $P$. kudriavzevii isolates, strains of the same species showed similar FV values (M. pulcherrima 1.02$1.26 \mathrm{~g} \mathrm{CO}_{2} / 100 \mathrm{ml}$; H. uvarum 2.12-2.13; Star. bacillaris 2.84; L. thermotolerans 3.88-4.01; S. cerevisiae 5.11-5.89) (Table 5). $M$. pulcherrima and H. uvarum strains showed a FP value lower of $4 \mathrm{~g} \mathrm{CO}_{2} / 100 \mathrm{ml}$; all $L$. thermotolerans strains, the unique strain of Star. bacillaris and the strain T24 of P. kudriavzevii exhibited values ranging from 6.50 to 7.30 ; while P. kudriavzevii T28 a value of about 8.30. S. cerevisae strains, as expected, showed higher FP values, if compared to non-Saccharomyces (from 8.78 to $\left.10.04 \mathrm{~g} \mathrm{CO}_{2} / 100 \mathrm{ml}\right)$. By HPLC analysis of wines at the end of fermentation (no weight change of fermentation flasks, in $48 \mathrm{~h}$ ), M. pulcherrima and of $H$. uvarum strains were able to produce $<5 \%$ of ethanol (Table 5 ). However, both strains of $M$. pulcherrima produce undetectable $(<0.15 \mathrm{~g} / \mathrm{l})$ amounts of acetic acid, a very high quantity of succinic acid (about $10.5 \mathrm{~g} / \mathrm{L}$ ), and a medium level of glycerol (about $5.5 \mathrm{~g} / \mathrm{l}$ ). By contrast, $H$. uvarum strains produced 1.0-1.2 g/l of acetic acid, 1.0-1.2 g/l of succinic acid and a lower amount of glycerol (4.1-4.7 g/l). Star. bacillaris strain T13 was able to produce a wine with about $10 \%$ of ethanol 
TABLE 4 | Technological characteristics of yeasts collected during this study.

\begin{tabular}{|c|c|c|c|c|c|c|c|c|c|c|c|c|}
\hline \multirow[t]{2}{*}{ Species } & \multirow{2}{*}{$\begin{array}{l}\text { No. of } \\
\text { isolates }\end{array}$} & \multirow{2}{*}{$\begin{array}{l}\text { aEthanol } \\
\text { resistance }\end{array}$} & \multirow{2}{*}{$\begin{array}{l}{ }^{\mathrm{b}_{2}} \mathrm{O}_{5} \mathrm{~S}_{2} \\
\text { resistance }\end{array}$} & \multirow{2}{*}{$\begin{array}{l}{ }^{c} \text { Type of } \\
\text { growth }\end{array}$} & \multirow{2}{*}{$\begin{array}{c}\stackrel{\mathrm{d}_{\mathrm{H}_{2}} \mathrm{~S}}{\text { production }}\end{array}$} & \multirow{2}{*}{$\begin{array}{c}{ }^{\text {e}} \text { Antagonistic } \\
\text { activity }\end{array}$} & \multicolumn{6}{|c|}{ Enzymatic activities } \\
\hline & & & & & & & fCELL & fARB & fESC & $\mathbf{f}_{\text {MUG }}$ & ${ }^{f}$ pNPG & gEST \\
\hline M. pulcherrima & 5 & 4,5 & 200 & $\mathrm{D}$ & $M$ & 2 & + & + & M & $\mathrm{L}, \mathrm{M}, \mathrm{H}$ & $M$ & - \\
\hline Star. bacillaris & 1 & 10 & 200 & $\mathrm{D}$ & $\mathrm{H}$ & - & - & - & $\mathrm{L}$ & $\mathrm{L}$ & $L$ & - \\
\hline P. kudriavzevii & 3 & $10-12$ & 200 & $D, S$ & $\mathrm{M}, \mathrm{H}$ & 1 & - & - & $\mathrm{L}, \mathrm{H}$ & $\mathrm{M}, \mathrm{H}$ & $L, M$ & - \\
\hline L. thermotolerans & 6 & 10 & 200 & $\mathrm{D}$ & $\mathrm{M}, \mathrm{H}$ & 4 & - & - & $\mathrm{L}$ & $\mathrm{L}, \mathrm{M}, \mathrm{H}$ & $L$ & - \\
\hline H. uvarum & 5 & 6,7 & 200 & $\mathrm{D}$ & $L$ & - & + & - & $\mathrm{M}, \mathrm{H}$ & $H$ & $L, M$ & - \\
\hline Pseud. aphidis & 2 & 6 & 200 & $\mathrm{~F}$ & $\mathrm{H}$ & - & - & - & $\mathrm{H}$ & $H$ & $\mathrm{H}$ & + \\
\hline S. cerevisiae (musts) & 13 & 15,16 & 200 & $\mathrm{D}$ & $\mathrm{M}, \mathrm{H}$ & 5 & - & - & $\mathrm{M}, \mathrm{H}$ & $\mathrm{M}, \mathrm{H}$ & $L$ & - \\
\hline S. cerevisiae (mix wines) & 8 & 15,16 & 200 & $\mathrm{D}$ & $\mathrm{M}, \mathrm{H}$ & 1 & - & - & $\mathrm{M}$ & $\mathrm{M}, \mathrm{H}$ & $L, M$ & - \\
\hline
\end{tabular}

aln YPD broth ethanol-added (4-16\% vol).

${ }^{b}$ In YPD broth $\mathrm{K}_{2} \mathrm{O}_{5} \mathrm{~S}_{2}$-added (50-200 $\mathrm{mg} / \mathrm{l}-50 \mathrm{mg} / \mathrm{l}$ increments).

${ }^{c}$ In tyndallized must $\left(21^{\circ} \mathrm{Brix}, \mathrm{pH} 3.50\right)$ after 4 days at $25^{\circ} \mathrm{C}$ : D, dispersed cells; S, surface growth; F, flocculent.

${ }^{d}$ On Biggy agar (Oxoid): L, low (Snow -White); M, medium (Hazelnut-Brown); H, high (Rust-Coffee).

e Number of isolates/strains showing antagonistic activity (Sangorrin et al., 2001).

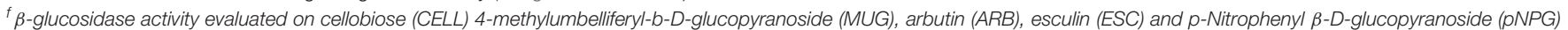
(Hernandez et al., 2002; Fia et al., 2005): +, positive; -, negative; L, low activity; M, medium activity; $H$, high activity.

gEsterase activity on Tween 80 (Slifkin, 2000).

$(9.91 \pm 0.24)$, and to entirely metabolize fructose and malic acid. By contrast, the wine still contained unfermented glucose (about $60 \mathrm{~g} / \mathrm{l})$, glycerol $(9.3 \mathrm{~g} / \mathrm{l})$, and acetic acid $(0.8 \mathrm{~g} / \mathrm{l})$. In spite of the similar ethanol content (10.7-11.0\%) P. kudriavzevii strains produced different fermentation by-products. In fact, the wine produced by strain T28 still contained about $45 \mathrm{~g} / \mathrm{l}$ of glucose, 1.1 $\mathrm{g} / \mathrm{l}$ of acetic and succinic acids and about $7.6 \mathrm{~g} / \mathrm{l}$ of glycerol; while, that produced by strain T24 contained even more unfermented sugars (about $86 \mathrm{~g} / \mathrm{l})$, glycerol (6.6 g/l), lactic (0.8 g/l), and succinic acid $(3.1 \mathrm{~g} / \mathrm{l})$ and did not contain detectable amount of acetic acid. L. thermotolerans produced slightly different wines depending on the strain: ethanol content ranged from 9.5 to $10.5 \%$, residual sugars from 60 to $70 \mathrm{~g} / \mathrm{l}$, succinic acid from 2.3 to $3.0 \mathrm{~g} / \mathrm{l}$, lactic acid from 1.3 to $2.5 \mathrm{~g} / \mathrm{l}$, while glycerol was always around $6.5 \mathrm{~g} / \mathrm{l}$ and acetic acid remained undetectable $(<0.15$ $\mathrm{g} / \mathrm{l})$. In wines produced by $S$. cervisiae strains some differences, depending on the strain used, emerged too. Two strains (MW16 and MW1), out 13, produced wines with a significant amount of unfermented fructose (15-20 g/l) and, as a consequence, with an alcoholic degree lower than 13\% (11.92 and 12.75\%, respectively). In the other, cases reducing sugars were detectable at low concentration $(<4 \mathrm{~g} / \mathrm{l})$ (wines produced by strains T52 and MW6) or undetectable (Table 5). In fact, the mean alcoholic degree of wines, excluding those produced by strains MW16 and MW1, was $13.8 \pm 0.28 \%$ (minimum $13.19 \pm 0.25 \%$, maximum $14.17 \pm 0.19 \%)$. The acetic acid production by $S$. cerevisiae strains ranged from 0.52 (T19) to $1.86 \mathrm{~g} / \mathrm{l}$ (MW10), even if, more than $50 \%$ of the strains produced $<0.6 \mathrm{~g} / \mathrm{l}$. Differences about glycerol production were also detected among wines produced by different strains of $S$. cerevisiae: from 5.35 of strain MW6 to $8.92 \mathrm{~g} / \mathrm{l}$ of MW10, the high acetic acid producer. However, $60 \%$ of strains produced $<6 \mathrm{~g} / \mathrm{l}$ of glycerol. Different amount of succinic acid were produced by $S$. cerevisiae strains: from 0.92 (MW5) to $2.25 \mathrm{~g} / \mathrm{l}$ (MW16). Finally, no significant differences in tartaric acid content were observed among wines produced by the different strains; by contrast, malic acid content of wines produced by strains MW17 and MW3 was significantly different: $3.63 \pm 0.22$ and $5.49 \pm 0.49 \mathrm{~g} / \mathrm{l}$, respectively.

\section{DISCUSSION}

As recently reviewed by Barata et al. (2012), grapes are characterized by a complex microbial ecology including filamentous fungi, yeasts, and bacteria with different physiological characteristics that mightily affect wine quality. Some species (parasitic fungi and environmental bacteria) may be only found in grapes, while others microorganisms, such as yeast, lactic acid bacteria, and acetic acid bacteria, may survive and/or grow during winemaking process. The ratio occurring among groups of microorganisms depends on different ecology factors: climate conditions, viticulture practices, grape ripening stage, and health status of grapes that direct influences the availability of nutrients available for the epiphytic microflora. As matter of fact, health status is the main factor affecting the microbial ecology of grapes: damaged grapes possess higher microbial numbers and greater species diversity if compared to the healthy ones (Barata et al., 2012). This study focused on grape yeast microbiota able to survive and or to grow during both middle and final stages of wine fermentation, and, therefore, potentially able to impact on wine quality. Aglianico grape samples were collected in different vineyards full covering the production area of the Taurasi DOCG. Grapes may potentially host different genera of non-Saccharomyces yeasts mostly belonging to the following genera: Metschnikowia, Dekkera, Pichia, Candida, Hanseniaspora, Kluyveromyces, Issatchenkia, Torulaspora, Debaryomyces, Saccharomycodes, Zygosaccharomyces, and Schizosaccharomyces spp. (Mills et al., 2008). In must, strains of these genera are subjected to a selective pressure exerted by different factors including: high 

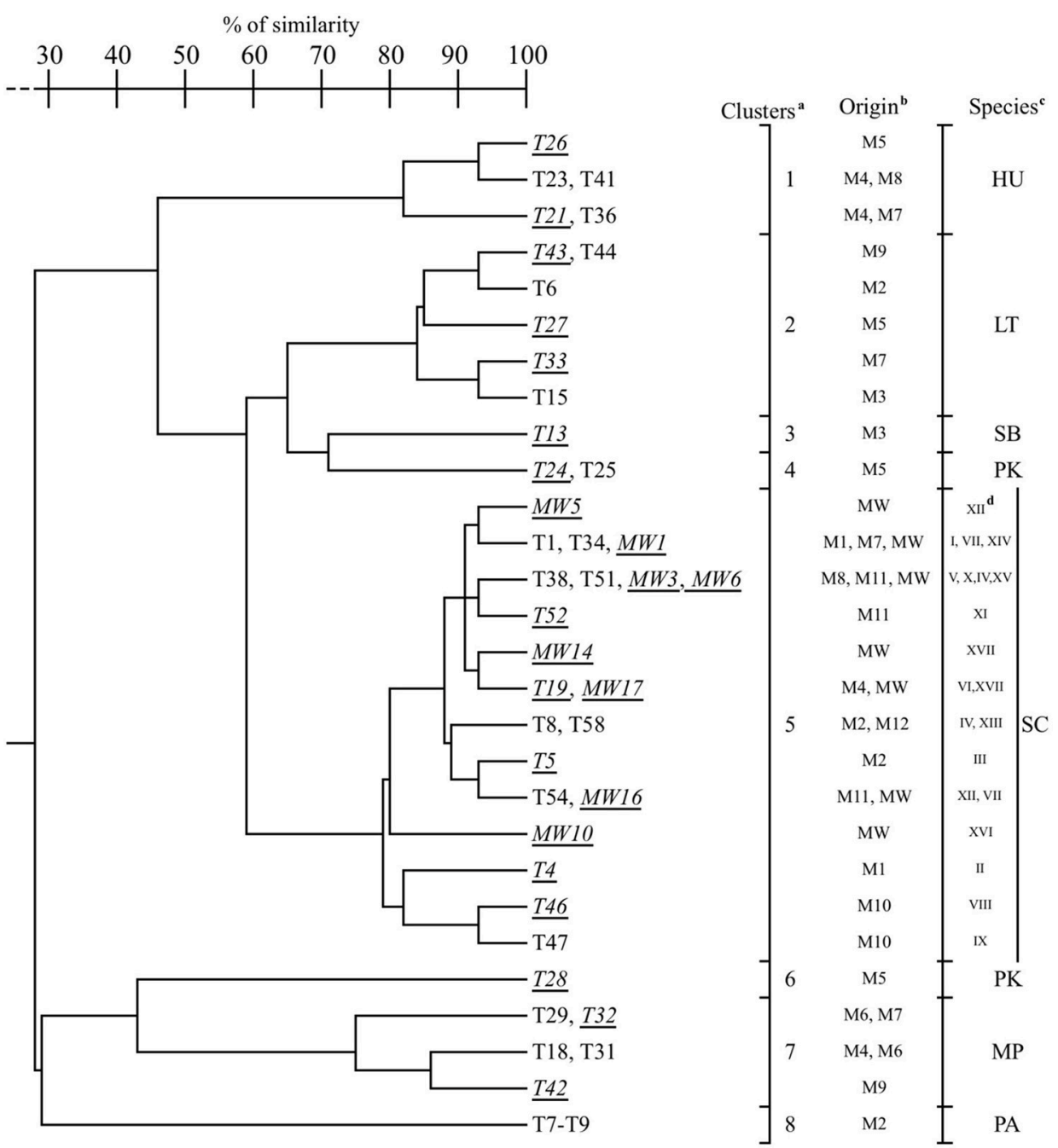

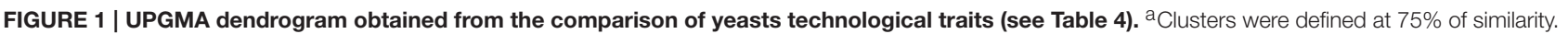
b Origin of isolates: M, must samples (see Table 1); MW, mix-wine. 'MP, M. pulcherrima; SB, Star. bacillaris; PK, P. kudriavzevii; LT, L. thermotolerans; HU, H. uvarum;

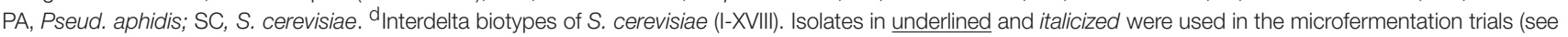
Table 5).

sugar content, high acidity, nutrient availability, low oxygen tension, increasing ethanol concentrations, and presence of specific inhibitors ( $\mathrm{SO}_{2}$, botriticin, medium chain fatty acids) (Ribereau-Gayon et al., 2006; Mills et al., 2008). Therefore, after few days of fermentation, the occurrence of grape yeasts may vary depending on the must characteristics. Thereafter, in natural fermentation, is expected that $S$. cerevisiae (poorly occurring on grape) become dominant due to its high adaptation of must-wine environment. Despite of their progressive reduction during wine fermentation, non-Saccharomyces yeasts are considered important members of must-wine ecosystem and able to increase the "complexity" of the wines sensory profiles through the production of a massive range of sensory-active compounds, actually higher than that usually associated to Saccharomyces alone (Fleet, 2008). At technological maturity $\left({ }^{\circ}\right.$ Babo higher then 19) Aglianico grapes still contain a high titratable acidity and low
pH (Gambuti et al., 2009). Musts produced by grapes sampled during this study were characterized by different titratable acidity (8.6-11.2 g/l), pH (3.10-3.40), and sugar content (19.0-21.6). Moreover, due to their different origin of grapes samples, musts may likely contain different amounts of available nitrogen, phenolic compounds, pesticide residues, and fermentation inhibitors, also. Such diversity may be partly explained by the chemical and microbiological differences detected among the musts after 9 days of fermentation. The applied strategy allowed to detect both Saccharomyces and non-Saccharomyces entities. Species retrieved during this study, with the exception of Pseud. aphids, were frequently detected on grapes, cellar equipment and along wine fermentations (Mills et al., 2008). Pseudozyma spp., yeast-like fungi (Ustilaginales), mostly epiphytic or saprophytic, not pathogenic to plants (Buxdorf et al., 2013) and presumably disseminated by migratory birds (Francesca et al., 2012), have 
already been detected on grape berries (Pantelides et al., 2015), and just once, by a culture-independent approach PCR-DGGE based, in commercial wines (Takahashi et al., 2014). In the present study, members of this genus were retrieved in one out of 12 musts at early stage of fermentation. Even if strains detected during this study showed high esterase and betaglucosidase activities, they do not seem to play any oenological role. However, Pseudozyma species have been reported to exhibit biological activity against powdery mildews and Botrytis cinerea (Buxdorf et al., 2013) and, due to their enzymatic activities, may represent an important source of microbial lipases, surfactants (Dimitrijević et al., 2011; Dziegielewska and Adamczak, 2013) and glucosidases (this study).

Because of their several negative fermentation characteristics, such as low fermentation power and rate, low $\mathrm{SO}_{2}$ resistance, and high production of acetic acid, ethyl acetate, acetaldehyde, and acetoin, non-Saccharomyces wine yeasts have been little considered as starter cultures in the past. However, as pointed out by this study, and previously by Comitini et al. (2011), some oenological traits of wine yeasts are species-specific (as ethanol resistance) and some are strain-specific $\left(\mathrm{SO}_{2}\right.$ resistance, type of growth, killer factor expression, $\mathrm{H}_{2} \mathrm{~S}$ production; enzymatic activities). Therefore, the strains selection among nonSaccharomyces may represent a profitable strategy to improve particular characteristics of wine (Suarez-Lepe and Morata, 2012). Despite of their low ethanol tolerance, as here reported, M. pulcherrima strains may exert antagonistic activity, high betaglucosidase activity, low acetic acid production (Comitini et al., 2011), and high succinic acid accumulations (this study). $M$. pulcherrima strains may inhibit the growth of some spoilage yeasts (Brettanomyces/Dekkera, Hanseniaspora, and Pichia) (Oro et al., 2014) by pigment formation, which depletes the free iron in the medium thus generating an environment unsuitable for microorganisms requiring such element for the growth (Sipiczki, 2006).

Isolates of $H$. uvarum analyzed during this study proved to be high acetic acid producers, low $\mathrm{H}_{2} \mathrm{~S}$ producers and potentially expressing beta-glucosidase activities. In fact, a recent study of Albertin et al. (2016) reports several extracellular enzymatic activities of oenological relevance (pectinase, chitinase, protease, $\beta$-glucosidase) in H. uvarum strains.

The two isolates of $P$. kudriavzevii (synonymously known as Issatchenkia orientalis) showed very different traits. Strain T28, showing antagonistic activity and showing the ability to hydrolyze esculine, MUG and pNPG, was able to produce a wine with $11 \%$ of ethanol, high concentration of acetic acid (1.1 $\mathrm{g} / \mathrm{l})$ and medium-high of glycerol (7.6 g/l). By contrast, strain T24 (antagonistic activity positive and beta-glucosidase negative) produced a wine with a similar alcoholic degree, containing undetectable amounts of acetic acid, low quantity of lactic acid and relatively high concentration of succinic acid. Killer toxin expression, lactic and succinic production were recently highlighted in strains of P. kudriavzevii (Bajaj et al., 2013; Xiao et al., 2014).

Strains of L. thermotolerans (formerly known as Kluyveromyces thermotolerans) produced wines with about $10 \%$ of ethanol, low acetic acid, high lactic, and relative high succinic acids, thus confirming data already reported by Comitini et al. (2011). Moreover, four out six strains were able to express killer toxin, while no strain analyzed by Comitini et al. (2011) expressed this character. Killer toxin production by Kluyveromyces thermotolerans IFO 1778 was reported by Kono and Himeno (1997).

This study also confirmed the fructophilic nature, the high glycerol production and the relative low ethanol and acetic acid synthesis by Star. bacillaris (synonym Candida zemplinina) during wine fermentation (Tofalo et al., 2012; Englezos et al., 2015). In addition, Tofalo et al. (2012) proved that strains of this species can also metabolized about $40 \%$ of the malic acid of must. Star. bacillaris strain T13, isolated during this study, was able to entirely metabolize malic acid; being this metabolite undetectable $(<0.25 \mathrm{~g} / \mathrm{l})$ by HPLC in the wine.

According to results, different biotypes of $S$. cerevisiae could be retrieved from the same grape sample; some biotypes could survive until the end of fermentation, while some other, not detectable in the grape or in must, become dominant in final product. In fact, as supposed by Sipiczki (2011), S. cerevisiae isolates of wine origin usually exhibit a significant biodiversity, due to the high propensity to genomic alteration of their genomes. In spite of the genetic diversity, S. cerevisiae strains exhibited an humble variability regarding their technological features and fermentation performances. Similar results were obtained by Capece et al. (2012): only three clusters out of 132 $S$. cerevisiae strains were obtained by statistical management of strains technological characterization. However, some strains isolated during this study showed undesirable characteristics as high $\mathrm{H}_{2} \mathrm{~S}$ and acetic acid production, and high residual fructose in wine.

As recently reviewed by Capozzi et al. (2015), the utilization of non-Saccharomyces/Saccharomyces multi-starter has been suggested by different researchers in order to mimic the spontaneous fermentation process and to avoid the risks of stuck or sluggish fermentations; in fact, the last years numerous investigations dealt with the biodiversity of non-Saccharomyces yeast isolated from grape juice and their use in multi-starter fermentations. Moreover, there is an increasing demand for autochthonous yeast, with the aim to select starter cultures better adapted to a definite grape must, thus exploiting the biodiversity of a specific "terroir" (see Capozzi et al., 2015). As consequence, specific selection projects are required in order to prevent negative impact autochthonous yeast on wine fermentation and to exploit their beneficial contributions to wine quality. In this study, the yeasts diversity occurring in grapes of a restrict area where high quality wines are produced was explored. By evaluating oenological traits, the potential of some isolated strains (non-Saccharomyces and S. cerevisae) in combination to modulate quality of Taurasi DOCG wine was highlighted.

In conclusion, apart from the local relevance of the present study, obtained outcomes clearly confirm that $S$. cerevisiae is a member of the vineyard microbiota. Moreover, the hypothesis formulated by Sipiczki (2011) according to which the genome of $S$. cerevisiae can change during fermentation (Fast Adaptive Evolution) seems to gain a further proof. 


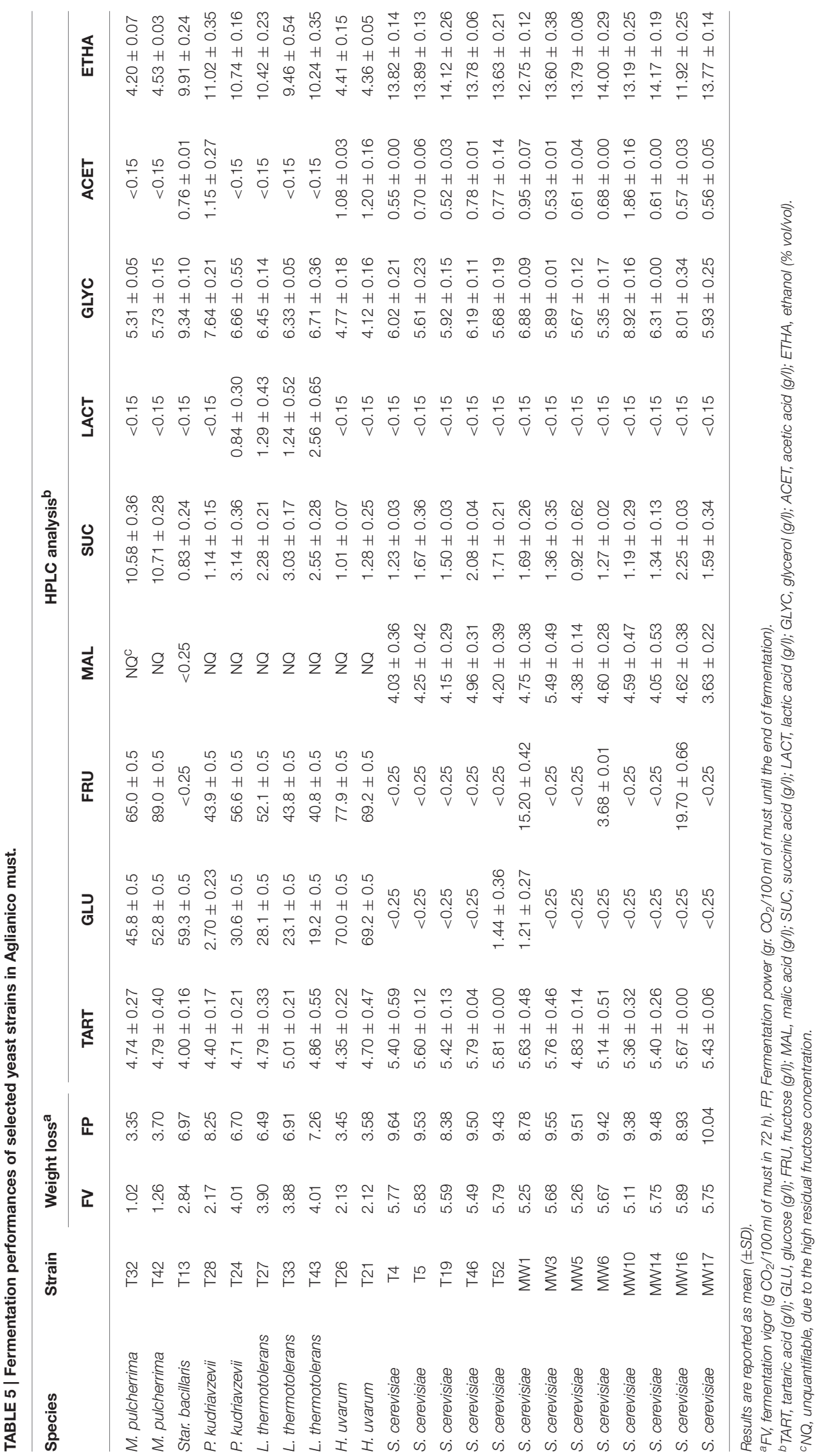


Finally, results support the idea, already reported by several authors (Comitini et al., 2011; Rantsiou et al., 2012; Domizio et al., 2014; Zuehlke et al., 2015), that must fermentation with mixed cultures may improve the quality and complexity of the final product.

\section{AUTHOR CONTRIBUTIONS}

GB designed the project. MA and GB performed all the experiments, wrote and edited the manuscript.

\section{REFERENCES}

Albertin, W., Setati, M. E., Miot-Sertier, C., Mostert, T. T., Colonna-Ceccaldi, B., Coulon, J., et al. (2016). Hanseniaspora uvarum from winemaking environments show spatial and temporal genetic clustering. Front. Microbiol. 6:1569. doi: 10.3389/fmicb.2015.01569

Aponte, M., and Blaiotta, G. (2016). Selection of an autochthonous Saccharomyces cerevisiae strain for the vinification of "Moscato di Saracena," a southern Italy (Calabria Region) passito wine. Food Microbiol. 54, 30-39. doi: 10.1016/j.fm.2015.10.019

Bajaj, B. K., Raina, S., and Singh, S. (2013). Killer toxin from a novel killer yeast Pichia kudriavzevii RY55 with idiosyncratic antibacterial activity. J. Basic Microbiol. 53, 645-656. doi: 10.1002/jobm.201200187

Barata, A., Malfeito-Ferreira, M., and Loureiro, V. (2012). The microbial ecology of wine grape berries. Inter. J. Food Microbiol. 153, 243-259. doi: 10.1016/j.ijfoodmicro.2011.11.025

Buxdorf, K., Rahat, I., Gafni, A., and Levy, M. (2013). The epiphytic fungus Pseudozyma aphidis induces jasmonic acid- and salicylic acid/nonexpressor of PR1-independent local and systemic resistance. Plant Physiol. 161, 2014-2022. doi: $10.1104 /$ pp. 112.212969

Capece, A., Romaniello, R., Siesto, G., and Romano, P. (2012). Diversity of Saccharomyces cerevisiae yeasts associated to spontaneously fermenting grapes from an Italian "heroic vine-growing area." Food Microbiol. 31, 159-166. doi: 10.1016/j.fm.2012.03.010

Capozzi, V., Garofalo, C., Chiriatti, M. A., Grieco, F., and Spano, G. (2015). Microbial terroir and food innovation: the case of yeast biodiversity in wine. Microbiol. Res. 181, 75-83.

Comitini, F., Gobbi, M., Domizio, P., Romani, C., Lencioni, L., Mannazzu, I., et al. (2011). Selected non-Saccharomyces wine yeasts in controlled multistarter fermentations with Saccharomyces cerevisiae. Food Microbiol. 28, 873-882. doi: 10.1016/j.fm.2010.12.001

Csoma, H., and Sipiczki, M. (2008). Taxonomic reclassification of Candida stellata strains reveals Frequent occurrence of Candida zemplinina in wine fermentation. FEMS Yeast Res. 8, 328-336. doi: 10.1111/j.15671364.2007.00339.x

Di Maio, S., Polizzotto, G., Di Gangi, E., Foresta, G., Genna, G., Verzera, A., et al. (2012). Biodiversity of indigenous Saccharomyces populations from old wineries of south-eastern Sicily (Italy): preservation and economic potential. PLoS ONE 7:30428. doi: 10.1371/journal.pone.0030428

Dimitrijević, A., Velickovic, D., Bezbradica, D., Bezbradica, F., Jankov, R., and Milosavic, N. (2011). Production of lipase from Pseudozyma aphidis and determination of the activity and stability of the crude lipase preparation in polar organic solvents. J. Serb. Chem. Soc. 76, 1081-1092. doi: 10.2298/JSC110428096D

Domizio, P., Liu, Y., Bisson, L. F., and Barile, D. (2014). Use of non-Saccharomyces wine yeasts as novel sources of mannoproteins in wine. Food Microbiol. 43, 5-15. doi: 10.1016/j.fm.2014.04.005

Dziegielewska, E., and Adamczak, M. (2013). Evaluation of waste products in the synthesis of surfactants by yeasts. Chem. Papers 67, 1113-1122. doi: 10.2478/s11696-013-0349-1

Englezos, V., Rantsiou, K., Torchio, F., Rolle, L., Gerbi, V., and Cocolin, L. (2015). Exploitation of the non-Saccharomyces yeast Starmerella bacillaris

\section{ACKNOWLEDGMENTS}

Authors wish to thank Dr. Michele Galasso for the technical support.

\section{SUPPLEMENTARY MATERIAL}

The Supplementary Material for this article can be found online at: http://journal.frontiersin.org/article/10.3389/fmicb. 2016.00809

(synonym Candida zemplinina) in wine fermentation: physiological and molecular characterizations. Intern. J. Food Microbiol. 199, 33-40. doi: 10.1016/j.ijfoodmicro.2015.01.009

Esteve-Zarzoso, B., Belloch, C., Uruburu, F., and Querol, A. (1999). Identification of yeast by RFLP of 5.8 rRNA gene and two ribosomal internal transcribed spacers. Int. J. Syst. Bacteriol. 49, 329-337. doi: 10.1099/00207713-4 9-1-329

Fia, G., Giovani, G., and Rosi, I. (2005). Study of $\beta$-glucosidase production by wine-related yeasts during alcoholic fermentation. A new rapid fluorimetric method to determine enzymatic activity. J. Appl. Microbiol. 99, 509-517. doi: 10.1111/j.1365-2672.2005.02657.x

Fleet, G. H. (2003). Yeast interactions and wine flavor. Int. J. Food Microbiol. 86, 11-22. doi: 10.1016/S0168-1605(03)00245-9

Fleet, G. H. (2008). Wine yeasts for the future. FEMS Yeast Res. 8, 979-995. doi: 10.1111/j.1567-1364.2008.00427.x

Francesca, N., Canale, D. E., Settanni, L., and Moschetti, G. (2012). Dissemination of wine-related yeasts by migratory bird. Environ. Microbiol. Rep. 4, 105-112. doi: 10.1111/j.1758-2229.2011.00310.x

Gambuti, A., Capuano, R., Lecce, L., Fragasso, M. G., and Moio, L. (2009). Extraction of phenolic compounds from 'Aglianico' and 'Uva di Troia' grape skins and seeds in model solutions: Influence of ethanol and maceration time. Vitis 48, 193-200.

Hernandez, L. F., Espinosa, J. C., Fernandez-Gonzales, M., and Briones, A. (2002). $\beta$-glucosidase activity in a Saccharomyces cerevisiae wine strain. Int. J. Food Microbiol. 80, 171-176. doi: 10.1016/S0168-1605(02) 00149-6

Kono, I., and Himeno, K. (1997). A novel killer yeast effective on Schizosaccharomyces pombe. Biosc. Biotech. Bioch. 61, 563-564. doi: 10.1271/bbb.61.563

Legras, J. L., and Karst, F. (2003). Optimisation of interdelta analysis for Saccharomyces cerevisiae strain characterisation. FEMS Microbiol. Lett. 221, 249-255. doi: 10.1016/S0378-1097(03)00205-2

Marinangeli, P., Angelozzi, D., Ciani, M., Clementi, F., and Mannazzu, I. (2004). Minisatellites in Saccharomyces cerevisiae genes encoding cell wall proteins: a new way towards wine strain characterisation. FEMS Yeast Res. 4, 427-435. doi: 10.1016/S1567-1356(03)00172-7

Mills, D. A., Phister, T., Neeley, E., and Johannsen, E. (2008). “Wine Fermentation," in Molecular Techniques in the Microbial Ecology of Fermented Foods, eds L. Cocolin and D. Ercolini (New York, NY: Springer), 161-192.

Nei, M., and Li, W. (1979). Mathematical model for studying genetic variation in thers of restriction endonucleases. Proc. Nat. Acad. Sci. U.S.A. 76, 5269-5273. doi: $10.1073 /$ pnas.76.10.5269

Oro, L., Ciani, M., and Comitini, F. (2014). Antimicrobial activity of Metschnikowia pulcherrima on wine yeasts. J. Appl. Microbiol. 116, 1209-1217. doi: 10.1111/jam.12446

Pallmann, C. L., Brown, J. A., Olineka, T. L., Cocolin, L., Mills, D. A., and Bisson, L. F. (2001). Use of WL medium to profile native flora fermentations. Am. J. Enol. Vitic. 52, 198-203.

Pantelides, I. S., Christou, O., Tsolakido, M.-D., Tsaltas, D., and Ioannou, N. (2015). Isolation, identification and in vitro screening of grapevine yeasts for the control of black aspergilli on grapes. Biol. Contr. 88, 46-53. doi: 10.1016/j.biocontrol.2015.04.021 
Pretorius, I. S. (2000). Tailoring wine yeast for the new millennium: novel approaches to the ancient art of winemaking. Yeast 16, 675-729. doi: 10.1002/1097-0061(20000615)16:8\&lt;675::AID-YEA585\&gt;3.0.CO;2-B

Rantsiou, K., Dolci, P., Giacosa, S., Torchio, F., Tofalo, R., Torriani, S., et al. (2012). Candida zemplinina can reduce acetic acid produced by Saccharomyces cerevisiae in sweet wine fermentations. Appl. Environ. Microbiol. 78, 1987-1994. doi: 10.1128/AEM.06768-11

Ribereau-Gayon, P., Dubourdieu, D., Doneche, B., and Lonvaud, A. (eds.). (2006). Handbook of Enology: The Microbiology of Wine and Vinifications, 2nd Edn., Vol. 1. Chichester: John Wiley \& Sons Ltd.

Sangorrin, M. P., Zajonskovsky, I. E., Lopes, C. A., Rodriguez, M. E., Giraudo de Van Broock, M. R., and Caballero, A. C. (2001). Killer behaviour in wild wine yeasts associated with Merlot and Malbec type musts spontaneously fermented from Northwestern Patagonia (Argentina). J. Bas. Microbiol. 41, 105-113. doi: 10.1002/1521-4028(200105)41:2\&lt;105::AID-JOBM105\&gt;3.0.CO;2-W

Sipiczki, M. (2006). Metschnikowia strains isolated from botrytized grapes antagonize fungal and bacterial growth by iron depletion. Appl. Environ. Microbiol. 72, 6716-6724. doi: 10.1128/AEM.01275-06

Sipiczki, M. (2011). Diversity, variability and fast adaptive evolution of the wine yeast (Saccharomyces cerevisiae) genome e a review. Ann. Microbiol. 61, 85-93. doi: 10.1007/s13213-010-0086-4

Slifkin, M. (2000). Tween 80 opacity test responses of various Candida species. J. Clin. Microbiol. 38, 4626-4628.

Suarez-Lepe, J. A., and Morata, A. (2012). New trends in yeast selection for winemaking. Trend. Food Sci. Technol. 23, 39-50. doi: 10.1016/j.tifs.2011.08.005

Takahashi, M., Ohta, T., Masaki, K., Mizuno, A., and Goto-Yamamoto, N. (2014). Evaluation of microbial diversity in sulfite-added and sulfite-free wine by culture-dependent and -independent methods. J. Biosci. Bioeng. 117, 569-575. doi: 10.1016/j.jbiosc.2013.10.012

Tofalo, R., Schirone, M., Torriani, S., Rantsiou, K., Cocolin, L., Perpetuini, G., et al. (2012). Diversity of Candida zemplinina strains from grapes and Italian wines. Food Microbiol. 29, 18-26. doi: 10.1016/j.fm.2011.08.014

Upholt, W. B. (1977). Estimation of DNA sequence divergence from comparison of restriction endonuclease didigests. Nuc. Acids Res. 4, 1257-1265. doi: 10.1093/nar/4.5.1257

Xiao, H., Shao, Z., Jiang, Y., Dole, S., and Zhao, H. (2014). Exploiting Issatchenkia orientalis SD108 for succinic acid production. Microb. Cell Fact. 13, 121. doi: 10.1186/s12934-014-0121-4

Zuehlke, J. M., Childs, B. C., and Edwards, C. G. (2015). Evaluation of Zygosaccharomyces bailii to metabolize residual sugar present in partially-fermented red wines. Fermentation 1, 3-12. doi: 10.3390/fermentation 1010003

Conflict of Interest Statement: The authors declare that the research was conducted in the absence of any commercial or financial relationships that could be construed as a potential conflict of interest.

Copyright $\odot 2016$ Aponte and Blaiotta. This is an open-access article distributed under the terms of the Creative Commons Attribution License (CC BY). The use, distribution or reproduction in other forums is permitted, provided the original author(s) or licensor are credited and that the original publication in this journal is cited, in accordance with accepted academic practice. No use, distribution or reproduction is permitted which does not comply with these terms. 